\title{
The design method of rubber-metallic expansion joint
}

https://doi.org/10.1515/eng-2018-0065

Received July 6, 2018; accepted October 1, 2018

\begin{abstract}
The paper present the method of designing a rubber expansion joints, intended for operation in the pressure class 25 bar. During the design used a numerical analysis, which based on the finite element method (FEM). The results from experimental test were used to correctly modeled the rubber or polyamide reinforcement. Basis on the obtained results, the hyperelastic model of the rubber was prepared, then the design of the rubber expansion joint was tested in different load case, i.e tensile or compressive deflection and pressurization.
\end{abstract}

Keywords: rubber, modeling, hyperelastic, FEM, design

\section{Introduction}

The rubber expansion joint is an elastic element of the pipeline system whose main task is to minimize the thermal and mechanical deflections as well as dampening of the noises and vibrations [1]. The main part of the expansion joint is elastic diaphragm made of rubber and a reinforcing layer. Usually the diaphragm is embedded in the metal flanges used for joining with the pipeline system Fig. 1.

The elastic diaphragm consists of several layers; internal, reinforced and external - Fig. 2. The internal layer plays the protective role for subsequent reinforcing layers. The reinforcing layer is usually made from polyamide or aramid fiber. There is an important element since its qual-

\footnotetext{
Przemysław Jaszak: Wroclaw University of Science and Technology, Department of Mechanical and Power Engineering, Wybrzeże Wyspiańskiego Street 27, 50-370 Wrocław, Poland, E-mail: przemyslaw.jaszak@pwr.edu.pl

Janusz Skrzypacz: Wroclaw University of Science and Technology, Department of Mechanical and Power Engineering, Wybrzeże Wyspiańskiego Street 27, 50-370 Wrocław, Poland, E-mail janusz.skrzypacz@pwr.edu.pl

*Corresponding Author: Konrad Adamek: Technology and R\&D in company Gambit Lubawka Sp. z o.o., Wojska Polskiego Street 16, 58-420 Lubawka, Poland, E-mail: konrad.adamek@gambitgl.pl
}

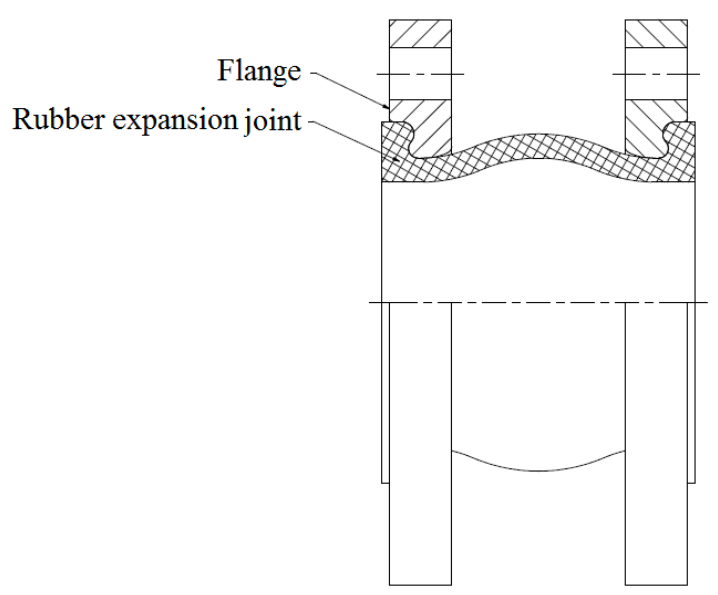

Figure 1: Rubber expansion joint with metallic loose flanges

ity influences the durability and strength of the expansion joint. The last layer, that is, the external one is protection against atmospheric agents as well as it binds the all elements into one composite piece.

The adequate selection of the rubber onto each layer of the expansion joint provides its resistance against different aggressive media. Table No 1 presents the main application of expansion joint depending on type of rubber used as the internal layer.

It is worth to mention that the rubber expansion joint is not a supporting element of the pipeline system. The proper scheme of its installation is presented in Fig. 3, where expansion joint is located between two fixed supports.

The displacements of the pipeline which are mitigated by means of the expansion joint could be distinguished into three basic groups:

- axials - (compressive or tensile) Fig. 4a and Fig. 4b,

- lateral Fig. 4c

- angular Fig. 4d 
Table 1: Application of the expansion joint depending on the rubber.

\begin{tabular}{ll}
\hline Internal layer & The most widely used \\
\hline NR & Abrasive materials, sewages, sea water \\
CR & Cold water, sea water, cold air \\
NBR & Oil, gasoline, gas, compressed air \\
NBR/PVC & Petrol, hydraulic oil \\
EPDM & Hot water, cooling water, acids, diluted chlorine solutions \\
CSM & Acids and alkaline solutions \\
IIR & Hot compressed air, alkalines \\
HNBR & Hot oil $120^{\circ}$ C, mixtures of oil and water \\
PTFE & Extremelly agressive agents \\
\hline
\end{tabular}

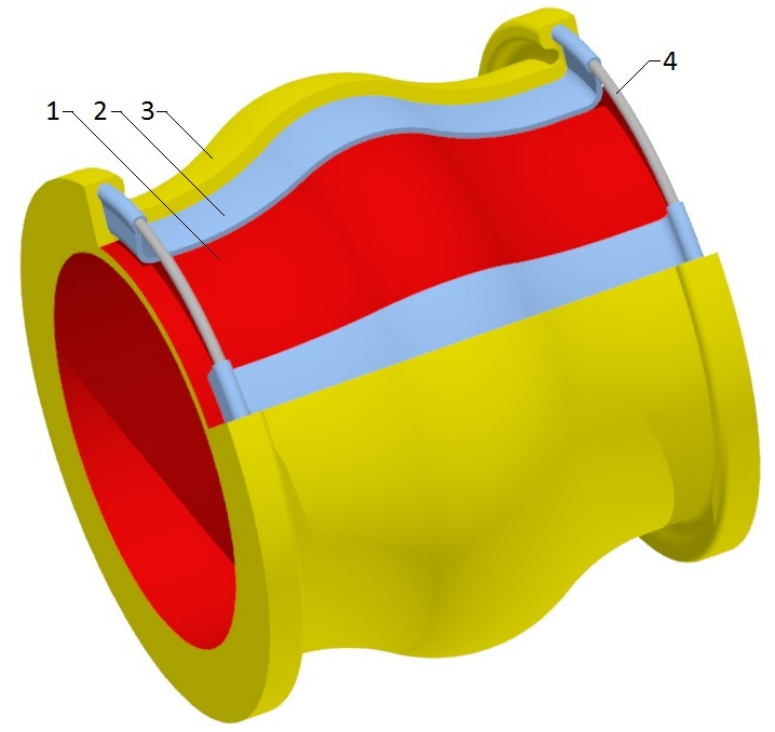

Figure 2: The design of elastic diaphragm: 1-internal layer; 2reinforcing layer; 3-external layer; 4-metallic wire

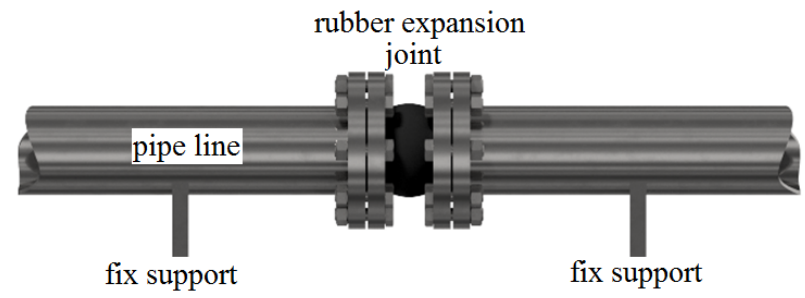

Figure 3: Scheme of the installation of the expansion joint in pipeline system a)

b)

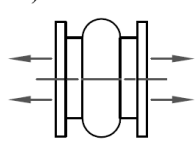

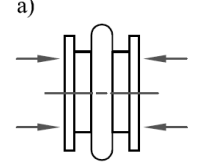

c)

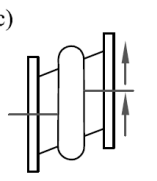

d)

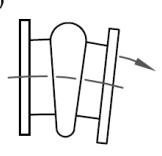

Figure 4: The displacement of the expansion joint: a) compressive; b) tensile; c) lateral; d) angular
Guidelines for tests conditions of the rubber expansion joint are included in [1]. The main procedures are:

- Internal pressure test at room temperature (the compensator should be withstand the test pressure equals 20 bar, for 1 hour)

- Internal pressure test at $100^{\circ} \mathrm{C}$ temperature (the compensator should be withstand the test pressure equals 20 bar, for 1 hour)

- Flexibility test (at room and $100^{\circ} \mathrm{C}$ temperature with internal pressure 10 bar)

- Ageing test (at $100^{\circ} \mathrm{C}$ and pressure $10 \mathrm{bar}$ ).

The rubber expansion joints are widely available on the market, their are mainly dedicated to the maximum pressure class PN16, i.e. the maximum working pressure is 16 bar. However, there are installations where higher pressure is required, therefore, special solutions are necessary. In this paper the design method of such an expansion joint was presented.

\section{The design method of expansion joint in numerical way}

To design such structures as elastic composite diaphragm is very complex since the elements made of rubber exhibit strongly non-linearity between the stress and strain relationship. In this case the best solution is to use numerical methods. One of them is a finite element method FEM. Modeling of the hyperplastic material like rubber in FEM includes adequate reflect of the real material by constitutive model.

For this reason, it is necessary to carry out experimental tests of the rubber in a multidirectional state of stress and strain. Then, based on the experimental data, the material constants of the constitutive hyperelastic model are 

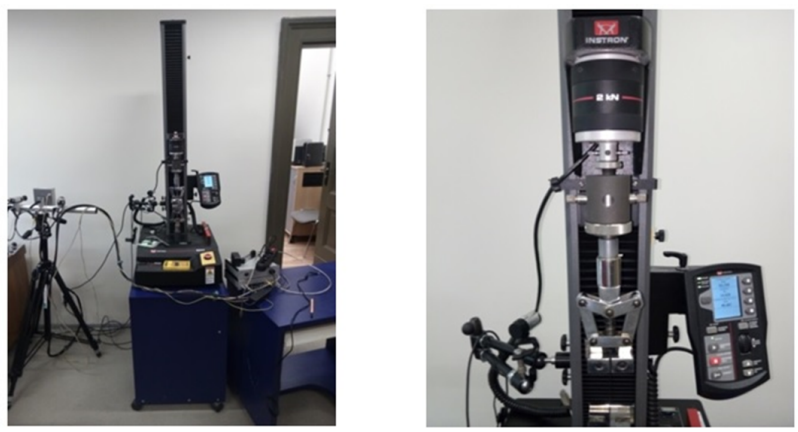

Figure 5: Test rig Instron model 5944

determined. The whole process of designing rubber expansion joint in FEM can be divided into a few basic steps:

- Testing of rubber materials,

- Adapting of the hyperelastic mathematical model,

- Preparation of the geometrical model,

- Setting the boundary conditions,

- Analyzing of the results obtained from the calculations.

\subsection{Test of materials}

To perform the elastic diaphragm the EPDM and NBR rubber were selected. Those materials are commonly used to the production of the elastic diaphragm of the expansion joint which are utilized in the industry. The both materials meet general requirement of the maximum operating temperature for the rubber expansion joint which equals $130^{\circ} \mathrm{C}$. The other kind of rubbers are rather dedicated in special cases, for instance in a higher operating temperatures or in applications where an aggressive media are transported. The hardness of both materials was 65 Shore. First, the tests of uniaxial tension were carried out in line with $[2,3]$. The experiment was conducted by means of Instron test rig presented in Fig. 5.

The aim of the test was to determine the stress $(\sigma)$ and strain $(\epsilon)$ relationship in uniaxial state of deformation. The exemplary characteristic of uniaxial tension of the NBR rubber was shown in Fig. 6.

The second test was equibiaxial tension. Due to lack of the proper standards in this test the bubble inflation method was used in accordance with [4-9].

This method consisted of pressurization of the rubber disc located between two metallic flanges - Fig. 7a and recording its deformation under increasing nitrogen pressure - Fig. $7 \mathrm{~b}$. The scheme of the test rig was presented in Figure 7c. The exemplary registered pictures of the de-

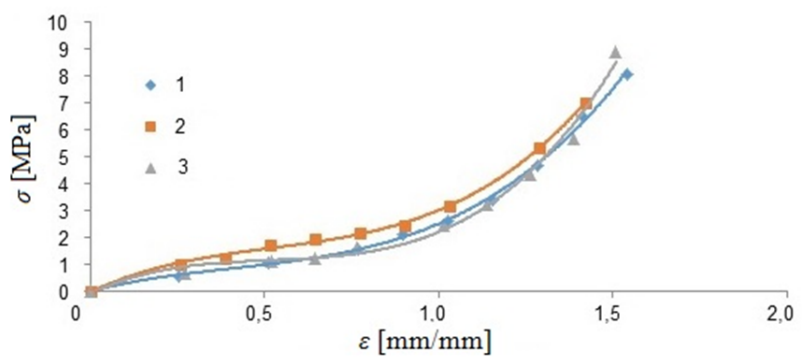

Figure 6: Uniaxial tension of the NBR $65^{\circ}$ Sha a) diaphragm

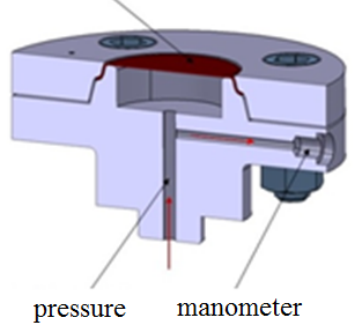

c) b)

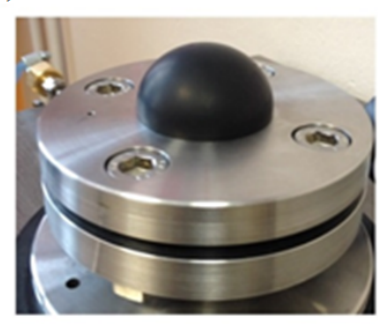

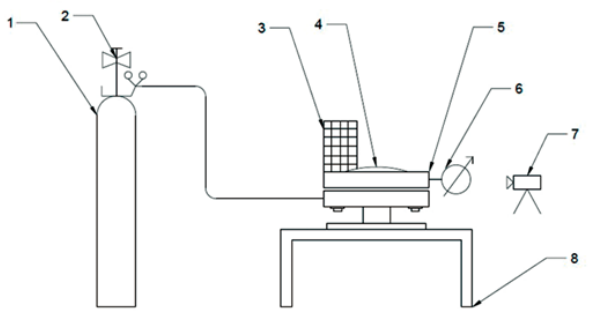

Figure 7: Test rig to biaxial stretch of rubber by means of bubble inflated method a) flange joint, b) view of inflated diaphragm, c) scheme of the test rig 1- reservoir, 2-regulating valve, 3-milimetric scale, 4- rubber sample, 5-flange joint, 6-manometer, 7-camera, 8-tablle

formed mode of the rubber sample were shown in Fig. 8 .

The engineering strain in the bubble pole were estimated by means of the following formula [4]:

$$
\epsilon_{x}=\epsilon_{y}=-\frac{1}{\epsilon_{z}}=-\frac{1}{2} \ln \left(\frac{t}{t_{0}}\right)=\ln \left(1+\left(\frac{h}{R}\right)^{2}\right)
$$

where: $\epsilon_{x}, \epsilon_{y}, \epsilon_{z}$ - directional strain respectively in axis $\mathrm{x}, \mathrm{y}, \mathrm{z} ; \mathrm{t}_{0}$ - nominal thickness of the rubber sample; $\mathrm{t}$ thickness under deflection; $h$-hight of the bubble ; $\mathrm{R}-$ radius of the flange's hole.

The engineering stress in the bubble pole was calculated by means of the following formula [4]:

$$
\sigma_{x}=\sigma_{y}=\frac{p R}{2 t_{0}}
$$

Applying the formulas (1) and (2) in the function of the pressure, the stress - strain relationship could be plot- 

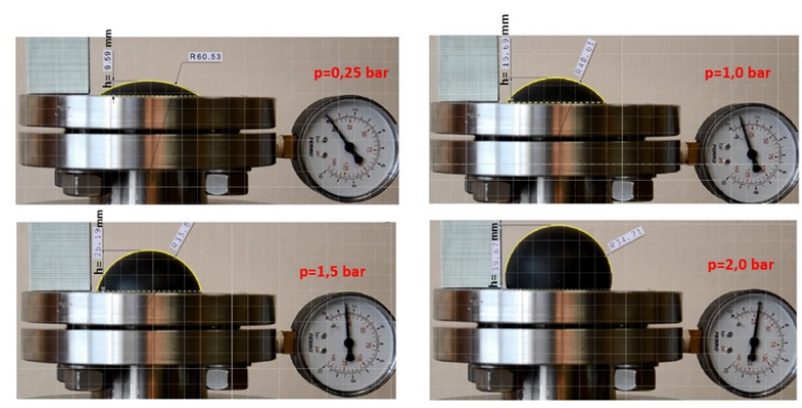

Figure 8: The deflection of the rubber samples under increasing pressure.

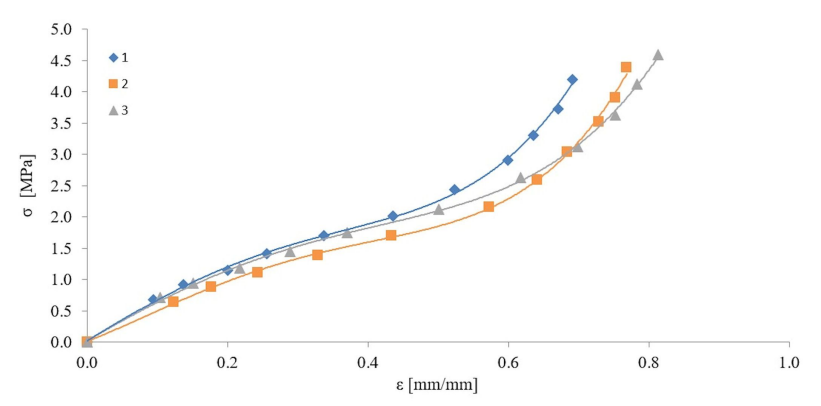

Figure 9: Biaxial tension of the NBR $65^{\circ}$ Sha

ted as a biaxial characteristic presented in Fig. 9. The mechanical strength of the rubber under biaxial deflection is prominently lower than uniaxial because rupturing took place at twice lower stress and strain.

\subsection{The hyperelastic model of the rubber}

To reflect the rubber behaviour the tri-parameric hiperelastic model proposed by Mooneya-Rivlina (M-R) was used [10-13]. The density of the elastic strain energy is described by formula (3):

$$
W=\mathrm{C}_{10}\left(\bar{I}_{1}-3\right)+\mathrm{C}_{01}\left(\bar{I}_{2}-3\right)+\mathrm{C}_{11}\left(\bar{I}_{1}-3\right)\left(\bar{I}_{2}-3\right)
$$

where: $\mathrm{C}_{10}, \mathrm{C}_{01}, \mathrm{C}_{11}$ - material constants, $\mathrm{I}_{1}, \mathrm{I}_{2}$-CouchyGreen strain invariants.

The values of the constants $\mathrm{C}_{10}, \mathrm{C}_{01}, \mathrm{C}_{11}$ were determined based on uniaxial and biaxial tests. In Fig. 10 the fitting curves of the M-R model to the experimental data were presented.

\subsection{Geometrical model and boundary conditions}

Based on geometrical model of the elastic diaphragm (Fig. 11a) the numerical model (Fig. 11b) was prepared. The

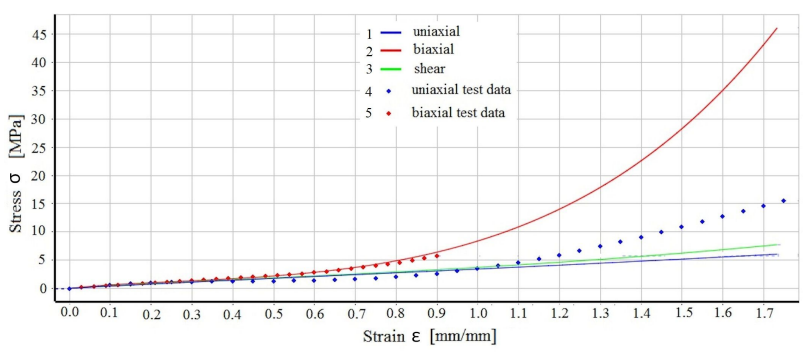

Figure 10: Fitting curves of the M-R model to experimental data: 1 - approximation of the uniaxial tensile ; 2 - approximation of the biaxial tensile; 3

approximation of the uniaxial shear -; 4 - experimental data set of the uniaxial tensile; 5 - experimental data set of the biaxial tensile a)

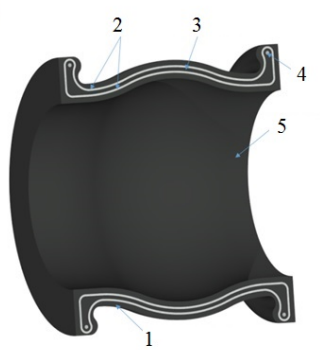

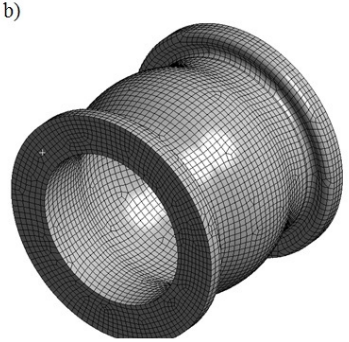

Figure 11: a) geometrical model: 1 - external layer, 2 - reinforcement, 3 - mid layer, 4 - wire, 5 - internal layer; b) discretized model

discretization of the geometry was performed by hexagon elements with a higher shape function. The contact between two element (polyamide layer and rubber layer) was set as a bonded. It reflected a real behavior of this structure because during the curing process the both materials were stuck together. The steady state of structural analysis was set.

In the Fig. 12 the boundary condition of the numerical model was presented.

The following load cases of the elastic diaphragm were analyzed.

- Internal pressure in range from 10 to 25 bar,

- compression/tension deflection up to $20 \mathrm{~mm}$,

- lateral deflection up to $20 \mathrm{~mm}$,

- angular deflection up to $20^{\circ}$. 

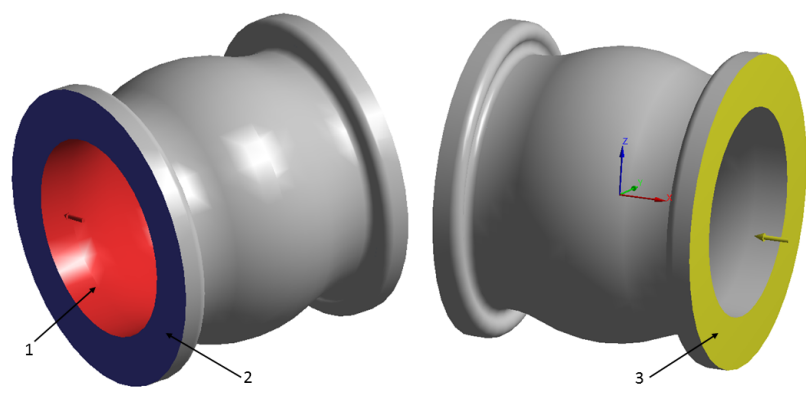

Figure 12: Boundary condition of the elastic diaphragm: 1 -the surface where the internal pressure was applied; 2 - the plane where fixed support was applied; 3 - the plane where displacements were applied.

The M-R model (3) was prepared in two configurations for EPDM and NBR rubber for which the material constants equal $\mathrm{C}_{10 E P D M}=0,554, \mathrm{C}_{01 E P D M}=0,003, \mathrm{C}_{11} 1_{E P D M}$ $=0,012$ and $\mathrm{C}_{10 N B R}=0,964, \mathrm{C}_{01 N B R}=-0,273, \mathrm{C}_{11 N B R}=$ 0,066 respectively. In accordance whit the standardized construction of the elastic diaphragm its reinforcing layer (in the form of crossed braided mesh) is an circumferentially wound inside the structure. So, some fibers of the polyamide layer are parallel to the axis of the diaphragm and the other are oriented in perpendicular way. Therefore, the orthotropic model of the polyamide was used. The material properties of the polyamide model were compiled in Table 2.

\section{Results}

The main aim of the numerical calculation was to determine the allowable displacement of the elastic diaphragm in defined directions at constant pressure. The Figures 13 and 14 depict the exemplary maps of von Misses stress distribution of the elastic diaphragm in a selected deformation mode.

Based on these maps in the Fig. 13b and $14 \mathrm{~b}$ it was observed that the highest stress occurs in the reinforcing layer. The exemplary chart of the stress in the reinforcing layer in the function of deformation increase was shown in Fig. 15. The allowable stress of this material is $110 \mathrm{MPa}$. Therefore, exceedance of this value determined the maximum displacement of the elastic diaphragm in particular direction. These maximum displacements for all deflecting mode were compiled in Table 3.
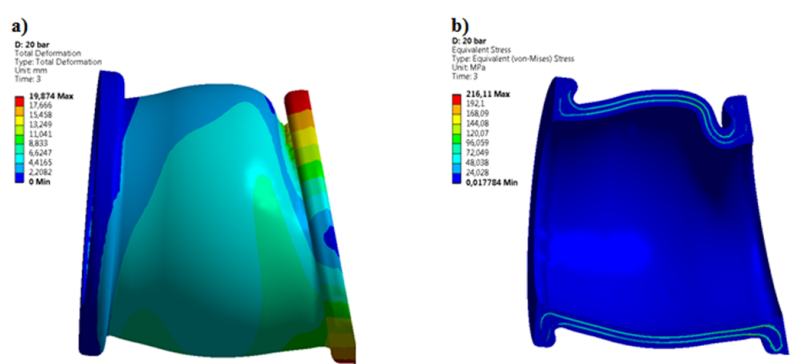

Figure 13: The deflection and von Misses stress distribution of the elastic diaphragm made of EPDM rubber. Load case: angular deflection at 15 deg. and internal pressure 20 bar, a) generalized deflection, b) von Mises stress distribution

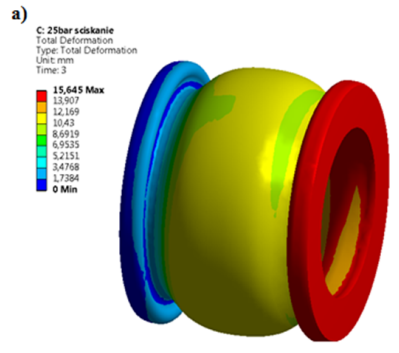

b)

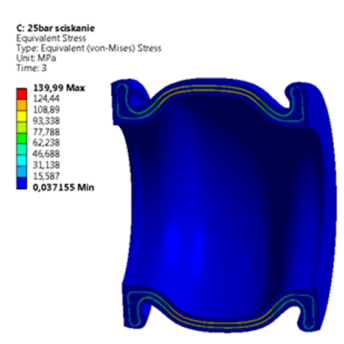

Figure 14: The deflection and von Misses stress distribution of the elastic diaphragm made of EPDM rubber. Load case: compressive deflection at 15 deg. and internal pressure 20 bar, a) generalized deflection, b) von Mises stress distribution

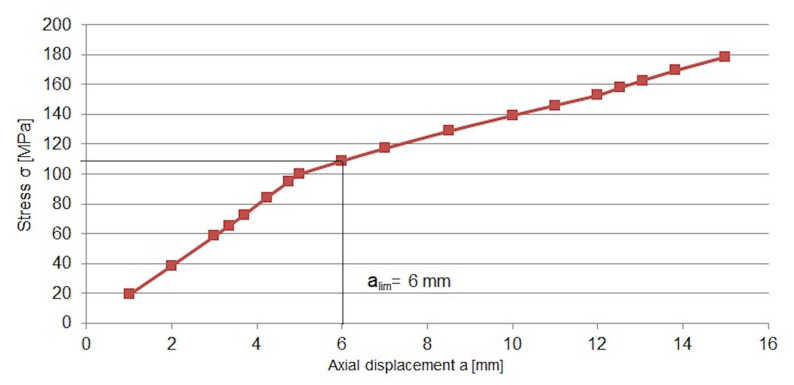

Figure 15: The von Misses stress in reinforcing layer depending on axial tensile displacement and internal pressure 25 bar for elastic diaphragm made of EPDM rubber. 
Table 2: Mechanical properties of the polyamide fiber of $1 \mathrm{~mm}$ thickness [14]

\begin{tabular}{cccccc}
\hline \multicolumn{2}{c}{$\begin{array}{c}\text { Longitudional } \\
\text { deformation module }\end{array}$} & \multicolumn{2}{c}{$\begin{array}{c}\text { Form deformation } \\
\text { module }\end{array}$} & \multicolumn{2}{c}{ Poisson ratio } \\
\hline $\begin{array}{c}\text { Axis } \\
\text { direction }\end{array}$ & $\begin{array}{l}\text { Value } \\
\text { [MPa] }\end{array}$ & Plane & Value & Plane & Value \\
\hline X & 1200 & XY & 400 & XY & 0,43 \\
Y & 1200 & YZ & 400 & YZ & 0,43 \\
$Z$ & 500 & XZ & 200 & XZ & 0,35 \\
\hline
\end{tabular}

Table 3: The maximum displacement of the elastic diaphragm depending on internal pressure

\begin{tabular}{cccccc}
\hline \multirow{2}{*}{ Rubber } & $\begin{array}{c}\text { Pressure } \\
\text { [bar] }\end{array}$ & \multicolumn{5}{c}{ Displacement } \\
\cline { 2 - 6 } & & $\begin{array}{c}\text { Compression } \\
c_{\text {lim }}[\mathrm{mm}]\end{array}$ & $\begin{array}{c}\text { Tension } \\
a_{\text {lim }}[\mathrm{mm}]\end{array}$ & $\begin{array}{c}\text { Lateral } \\
r_{\text {lim }}[\mathrm{mm}]\end{array}$ & $\begin{array}{c}\text { Angular } \\
\alpha_{\text {lim }}\left[{ }^{\circ}\right]\end{array}$ \\
\hline \multirow{3}{*}{ EPDM } & 10 & 13 & 10 & 15 & 8 \\
\cline { 2 - 6 } & 15 & 13 & 8 & 15 & 7 \\
\cline { 2 - 6 } & 20 & 12 & 7 & 15 & 7 \\
\cline { 2 - 6 } NBR & 25 & 10 & 6 & 12 & 5 \\
\cline { 2 - 6 } & 10 & 13 & 8 & 15 & 8 \\
\cline { 2 - 6 } & 15 & 12 & 6 & 15 & 8 \\
\cline { 2 - 6 } & 20 & 12 & 5 & 12 & 5 \\
\hline
\end{tabular}

\section{Summary}

The finite element method is a helpful tool at designing and analyzing components made of rubber, especially in case a large deformation, since the rubber material exhibits a strong nonlinearity between strain and stress relationship. Using this method for designing of the rubber expansion joint enabled to checked how are the permissible deflection of the elastic diaphragm in particular directions, providing its failure-free work. It turn out that the maximum stress in the elastic diaphragm occurred in reinforcing layer regardless of kind of rubber used for internal and external layers.

\section{References}

[1] DIN 4809 Expansion joints made of elastomer compound materials (rubber expansion joints) for water heating plants, November 1986

[2] PN ISO 37:2007, Rubber, Vulcanized Or Thermoplastic - Determination Of Tensile Stress-strain Properties,

[3] DIN 535504 Testing of rubber-Determination of tensile strength at brake, tensile stress at yield, elongation and stress values in a tensile test, 2017

[4] Seibert H., Scheffer T., Diebels S. "Biaxial Testing of Elastomers - Experimental Setup, Measurement and Experimental Optimi- sation of Specimen's Shape", TECHNISCHE MECHANIK, 34, 2, (2014), 72 - 89: July 15, 2013,

[5] Murphy J.S., Hanley N., The Significance of Equi-biaxial Bubble Inflation in Determining Elastomeric Fatigue Properties, Elastomers, editor. A. Boczkowska, InTech 2012.

[6] Bojtos A., Ábrahám G., Optical measuring system for equibiaxial test of hyperelastic rubber-like materials, 9th Youth Symposium on Experimental Solid Mechanics, Trieste, Italy, July 7-10, 2010, 170-173,

[7] Brieu M., Diani J., Bhatnagar N., A New Biaxial Tension Test Fixture for Uniaxial Testing Machine-A Validation for Hyperelastic Behavior of Rubber-like Materials, Journal of Testing and Evaluation, Vol. 35, No. 4.

[8] Murphy J. S., Hanley N., (2012), The Significance of Equi-biaxial Bubble Inflation in Determining Elastomeric Fatigue Properties, Published in the book Elastomers edited by Anna Boczkowska (ISBN 979-953-307-1019-5), InTech,

[9] Palmieri G., Chiappini G., Sasso M., Papalini S., Hyperelastic Materials Characterization by Planar Tension Tests and Fullfield Strain Measurement, Proceedings of the SEM Annual Conference, June 1-4, 2009 Albuquerque New Mexico USA 2009 Society for Experimental Mechanics Inc,

[10] Shahzad M., Kamran A., Zeeshan Siddiqui M., Farhan M., Mechanical Characterization and FE Modelling of a Hyperelastic Material, Material Research. Vol. 18 no. 5 São Carlos Sept./Oct. 2015,

[11] Ali A., Hosseini M., Sahari B.B., A Review of Constitutive Models for Rubber-Like Materials, American J. of Engineering and Applied Sciences, 232-239, 2010,

[12] Jakel R., Analysis of Hyperelastic Materials with MECHANICA, Presentation for the 2nd SAXSIM | Technische Universität Chem- 
nitz, 27. April $2010 \mid$ Rev. 1.0 - Theory and Application Examples,

[13] Santos D., Batalha G.F., Mechanical behaviour characterizing and simulation of polyacrylate rubber, Journal of Achievements in Materials and Manufacturing Engineering, Vol. 38, Issue 1, January 2010,

[14] Engineering data sources - Ansys Workbench 15.0. 